Audiology

\title{
Hearing threshold estimation by auditory steady state responses (ASSR) in children
}

\section{Stima di soglia mediante potenziali evocati uditivi di stato stazionario in età pediatrica}

\author{
C. Aimoni, L. Crema, S. Savini, L. Negossi, M. Rosignoli, L. Sacchetto, C. Bianchini, A. Ciorba \\ ENT \& Audiology Department, University Hospital of Ferrara, Italy
}

\section{SUMMARY}

Hearing threshold identification in very young children is always problematic and challenging. Electrophysiological testing such as auditory brainstem responses (ABR) is still considered the most reliable technique for defining the hearing threshold. However, over recent years there has been increasing evidence to support the role of auditory steady-state response (ASSR). Retrospective study. Forty-two children, age range 3-189 months, were evaluated for a total of 83 ears. All patients were affected by sensorineural hearing loss (thresholds $\geq 40 \mathrm{~dB}$ HL according to a click-ABR assessment). All patients underwent ABRs, ASSR and pure tone audiometry (PTA), with the latter performed according to the child's mental and physical development. Subjects were divided into two groups: A and B. The latter performed all hearing investigations at the same time as they were older than subjects in group A, and it was then possible to achieve electrophysiological and PTA tests in close temporal sequence. There was no significant difference between the threshold levels identified at the frequencies tested $(0.25,0.5,1,2$ and $4 \mathrm{kHz})$, by PTA, ABR and ASSR between the two groups (Mann Whitney U test, $\mathrm{p}<0.05$ ). Moreover, for group A, there was no significant difference between the ASSR and ABR thresholds when the children were very young and the PTA thresholds subsequently identified at a later stage. Our results show that ASSR can be considered an effective procedure and a reliable test, particularly when predicting hearing threshold in very young children at lower frequencies (including $0.5 \mathrm{kHz}$ ).

KEY WORDS: Sensorineural hearing loss $\bullet$ ASSR • ABR・Audiometry • Children

\section{RIASSUNTO}

Effettuare una stima di soglia in età pediatrica è compito spesso difficile e complesso. A tal proposito, i potenziali evocati uditivi del tronco $(A B R)$ rappresentano ancora la tecnica più affidabile per la definizione di soglia, sebbene il ruolo dei potenziali evocati uditivi di stato stazionario (ASSR) sia stato rivalutato negli ultimi anni. In questo studio retrospettivo sono stati valutati 42 bambini, di età compresa tra 3 e 189 mesi, per un totale di 83 orecchie. Tutti i pazienti inclusi sono risultati affetti da ipoacusia neurosensoriale ( $\geq 40 \mathrm{~dB} H L$ in base alla valutazione click-ABR). Tutti i pazienti sono stati sottoposti ad ABR, ASSR ed audiometria tonale, quest'ultima eseguita appena lo sviluppo psico-fisico del bambino lo ha consentito. I soggetti sono stati suddivisi in due gruppi: gruppo A e B, quest'ultimo ha effettuato tutte le indagini audiologiche quasi nello stesso momento, in quanto i bambini erano più grandi rispetto ai soggetti del gruppo A (in particolare sia le valutazioni elettrofisiologiche che l'audiometria tonale sono state eseguite quasi contemporaneamente). Non sono risultate differenze significative tra i livelli di soglia individuati, alle frequenze testate $(0,25,0,5,1,2$ e $4 \mathrm{kHz})$, mediante audiometria tonale, ABR e ASSR, tra $i$ due gruppi (test di U Mann Whitney, $p<0,05$ ). Inoltre, considerando i bambini del gruppo A, non si è rilevata alcuna differenza significativa tra le soglie identificate mediante ASSR e ABR rilevate quando i bambini erano molto piccoli, e le soglie di audiometria tonale identificate successivamente. Nella nostra esperienza quindi, i potenziali evocati uditivi di stato stazionario possono essere considerati una metodica efficace ed affidabile soprattutto nella stima di soglia dei bambini molto piccoli e per le basse frequenze (compreso 0.5 kHz).

PAROLE CHIAVE: Ipoacusia neurosensoriale $\bullet$ ASSR $\bullet$ ABR $\bullet$ Audiometria $\bullet$ Bambini

Acta Otorhinolaryngol Ital 2018;38:361-368

\section{Introduction}

Since normal hearing is a necessary condition for the spontaneous acquisition of oral ability and cognitive development ${ }^{1}$, hearing loss detection should be performed at the earliest possible age in order to provide timely interventions such as hearing aids or cochlear implants. In 2007, the Joint Committee on Infant Hearing (JCIH) recommended action as of 6 months, when treating congenital hearing loss in infants, in order to promote cognitive 
and linguistic development (2007 position statement). However, obtaining precise and objective hearing information in very young children, especially at mid-to-low frequencies, is still a challenging task. Conventional pure tone audiometry (PTA) remains a crucial test to describe the degree of hearing loss in subjects who are able to respond and cooperate; behavioural audiometry and/or visual reinforcement audiometry can be used when evaluating younger children ${ }^{2}$, while electrophysiological tests such as auditory brainstem responses (ABRs) are still the gold standard in very young and non-cooperating children. However, in recent years, an increasing number of clinical studies have examined the role of the auditory steady-state response (ASSR) for estimating hearing thresholds. ASSR are scalp-recorded potentials elicited by continuous amplitude and/or frequency-modulated tones ${ }^{3}$. These can be recorded by using two stimulation techniques: single frequency and multifrequency stimulation ${ }^{4}$. The application of ASSR has been studied in normal and hearing-impaired adults, children and infants ${ }^{5-7}$, and several advantages of this objective procedure have already been reported. In particular, the stimulus seems to be more frequency rangespecific, compared to clicks-evoked $\mathrm{ABR}^{8}$, and the measurement can provide hearing information even for individuals with profound hearing loss $(>90 \mathrm{~dB})^{9}$. Some authors have investigated the correlation between ASSR threshold prediction and hearing level determined by standard audiometry ${ }^{10-14}$. However experimental evidence in this area remains limited, especially in very young children affected by sensorineural hearing loss.

The aim of the present study is to verify, in a population of young children, the reliability of ASSR in: (i) identifying hearing threshold levels and (ii) predicting hearing threshold levels in very young children particularly at mid-tolow frequencies.

\section{Materials and methods}

Retrospective study. Forty-two children (22 males and 20 females), for a total of 83 ears tested, were included in this study: 41 children were affected by bilateral sensorineural hearing loss and 1 child by monolateral sensorineural hearing loss. Depending on age and time of audiological assessment, subjects were divided into two groups: we included 22 children, 43 ears (group A) born between November 2007 and May 2012, and 20 subjects, 40 ears (group B) born between October 1995 and August 2006. In group A, ASSR was carried out when subjects were between 3 and 121 months (mean age 27.22 months). In group B, ASSR was performed in older subjects, between 86 and 189 months (mean age 133.75 months). Pure tone audiom- etry was performed between 22 months and 131 months (median age 47.86) within group A, and between 86 and 189 months (median age 138.25 months) within group B. Therefore, the average time-interval between investigation by ASSR and pure tone audiometry was 22.41 months for group A and 4.37 months for group B.

All clinical charts were reviewed and data were collected retrospectively. Informed consent was obtained from all participants' parents, at the time of the first audiological investigation, according to current Italian law, and the search was carried out in compliance with the Helsinki Declaration.

Both groups were affected by moderate to severe sensorineural hearing loss (thresholds $\geq 40 \mathrm{~dB}$ HL according to a click-ABR assessment). Inclusion criteria were: normal ENT clinical findings, transient otoacoustic emissions (TEOAEs) failure and ABR threshold $\geq 40 \mathrm{~dB}$ HL in at least one ear. All patients underwent TEOAEs, ABR, ASSR, behavioural audiometry and pure tone audiometry (PTA), the latter performed later according to the child's mental and physical development. Subjects were included in group B based on the same criteria, but were older than those of group A at the time of audiological assessment: it was then possible to perform ASSR and PTA on the same session or in close temporal sequence. All investigations were performed at the ENT \& Audiology Department of the University Hospital of Ferrara.

TEOAEs were recorded using an AccuScreen device (Otometrics, Madsen). The clicks in the stimulus train followed a non- linear protocol and the click frequency was $60 \mathrm{~Hz}$. The stimulus level was set between 70-90 dB SPL. The automatic evaluation was based on the determination of the weighted average of the noise-level and the number of significant signal peaks. In all examined ears TEOAEs recorded failure.

ABR and ASSR responses were recorded by ICS Chartr (GN Otometrics, Mercury, Italy). ASSR responses were registered at single carrier frequencies $(500,1000,2000$, $4000 \mathrm{~Hz}$ ) using pure tone frequency with $25 \%$ modulation and by $100 \%$ amplitude modulation. ASSR values were detected To a 5\% error-margin. The amplification used for better detection of the signal was $200 \mathrm{k}$.

Carrier frequencies were 500, 1000, 2000 and $4000 \mathrm{~Hz}$, and were modulated respectively at $97,81,95$ and $88 \mathrm{~Hz}$ for the right ear and 95, 79, 94 and $85 \mathrm{~Hz}$ for the left ear. Signals were filtered using a high pass filter of $65 \mathrm{~Hz}$, and a low pass filter of $105 \mathrm{~Hz}$. Signal/noise average ratio was $+2 \mathrm{~dB}$ across all measurements. At each frequency the time limit for signal detection was set at 3 minutes. ABR were obtained by using transient clicks $(0.1 \mathrm{msec}$ with alternating polarity). ABR and ASSR were recorded 
Table I. Risk factors for congenital hearing loss across the group of children studied.

\begin{tabular}{lcc} 
Risk factors (JCIH 2007) & Group A (22 subjects) & Group B (20 subjects) \\
Family history of hearing loss & 1 & 5 \\
In-utero infections & 1 & 0 \\
Craniofacial anomalies & 1 & 3 \\
Syndromes associated with hearing loss & 4 & 1 \\
Neonatal intensive care $>5$ days & 2 & 2 \\
Prematurity $<37$ weeks & 2 & 2 \\
Hyperbilirubinaemia & 1 & 0 \\
Total & 12 & 13 \\
\hline
\end{tabular}

in spontaneously sleeping subjects using silver chloride cup electrodes, with the active and reference electrodes applied to the vertex and the mastoid, respectively. ABR and ASSR threshold identification were performed by decreasing steps of $10 \mathrm{~dB}$ SPL starting from the maximum intensity of stimulation ( $90 \mathrm{~dB} \mathrm{HL})$. For both techniques, threshold detection was identified as the minimum intensity level that could allow the identification of a clear electrophysiological response by the operator; each run was replicated at or near threshold.

PTA was performed by placing the child in a soundproof room, as soon as he/she was able to provide reliable responses. It was performed using headphones to assess air conduction and a bone vibrator for bone conduction; the better ear was evaluated first (sound-proof cabin model E2X2, roll 01008 220V 10A; Mercury, Milan, Italy; Amplaid audiometer, Amplaid, Milan, Italy, calibrated to ISO 9001 standards). The examination was conducted by an experienced audiometric technician or an experienced technician and an audiologist. The intensity of the acoustic signal was progressively reduced, using $5 \mathrm{~dB}$ steps, to assess the threshold level, frequency by frequency ${ }^{14}$.

\section{Statistical analysis}

The data collected were examined using the program SPSS, version Windows Base System (SPSS Inc., Chicago, IL, USA); The strength of association between the variables was quantified by Pearson's correlation test. To evaluate the differences between subpopulations we used the non-parametric Wilkoxon's test for pairwise comparisons and Mann Whitney's test for independent samples. The results were considered statistically significant for $\mathrm{p}$ values $<0.05(*)$.

\section{Results}

Twenty-two children (43 ears) were included in group A and 20 children (40 ears) in group B; risk factors for con-

Table II. Hearing threshold levels identified by ASSR, ABR and pure tone audiometry within groups A and B, across all the tested frequencies $(0.25,0.5,1$, 2 and $4 \mathrm{kHz}$ ).

\begin{tabular}{|c|c|c|c|c|c|c|c|c|c|c|}
\hline & & assr500 & assr1k & assr2k & assr4k & aud500 & aud1k & aud2k & aud4k & $a b r$ \\
\hline \multirow[t]{4}{*}{ GROUP B } & $\mathrm{N}$ & 32 & 14 & 14 & 28 & 40 & 37 & 37 & 39 & 33 \\
\hline & Min-Max & $20-90$ & $35-105$ & $40-100$ & $40-95$ & $10-110$ & $15-105$ & $10-105$ & $15-110$ & $20-90$ \\
\hline & Mean & 48.1 & 65.7 & 75.7 & 70.9 & 44.9 & 53.9 & 61.7 & 62.2 & 61,2 \\
\hline & St dev & 22.2 & 21.1 & 18.1 & 15.4 & 26.1 & 25.8 & 23.0 & 25.0 & 17.6 \\
\hline U test sig & & 0.49 & 0.65 & $0.04^{*}$ & $0,03^{*}$ & 0,05 & 0,19 & 0,52 & 0,60 & 0,36 \\
\hline \multirow[t]{4}{*}{ GROUP A } & $N$ & 38 & 17 & 12 & 30 & 43 & 43 & 43 & 43 & 40 \\
\hline & Min-Max & $25-85$ & $35-100$ & $40-95$ & $20-100$ & $15-80$ & $15-100$ & $15-110$ & $15-115$ & $20-85$ \\
\hline & Mean & 49.3 & 63.0 & 61.7 & 63.5 & 49.8 & 60.7 & 66.3 & 65.9 & 59.1 \\
\hline & St. dev & 16.8 & 21.6 & 13.5 & 13.1 & 14.7 & 19.1 & 19.2 & 23.2 & 13.1 \\
\hline \multirow[t]{3}{*}{ Total } & $\mathrm{N}$ & 70 & 31 & 26 & 58 & 82 & 80 & 80 & 82 & 73 \\
\hline & Mean & 48.8 & 64.2 & 69.2 & 67.1 & 46.6 & 57.6 & 64.2 & 64.1 & 60,1 \\
\hline & St. Dev & 19.3 & 21.1 & 17.3 & 14.6 & 20.0 & 22.5 & 21.0 & 24.0 & 15,2 \\
\hline
\end{tabular}


genital hearing loss were identified in 25 cases (59.5\%), 12 in group A (54.5\%) and 13 in group B (65\%), according to Joint Committee on Infant Hearing (JCIH 2007) criteria (Table I).

In Table II, we report the average hearing threshold levels identified by ASSR, ABR and PTA within both groups with the respective standard deviations (frequency range $=0.5,1,2$ and $4 \mathrm{kHz}$ ). Groups A and B showed overlapping threshold profiles for PTA and ASSR (Fig. 1). Comparison of the threshold levels identified at the different frequencies tested by pure tone audiometry and ABR revealed a significant difference among the two groups only at 2 and $4 \mathrm{kHz}$ (independent samples Mann Whitney $\mathrm{U}$ test, $\mathrm{p}<0.05$ ).

Nonetheless, in order to evaluate the reliability of ASSR, we calculated the differences, in decibels, between the thresholds obtained by PTA and ASSR (see also Table III). These data were obtained by subtracting threshold levels obtained by ASSR and PTA at each frequency $(0.5,1,2$ and $4 \mathrm{kHz}$ ). The average differences between the values obtained are shown as mean \pm standard deviation in Table III. This method has been applied for both groups. In particular, negative values indicate that the ASSR overestimates the threshold level, while positive values indicate that the ASSR underestimates the threshold level; where the values were close to 0 , the two methods did not show differences in threshold estimation. For each group and for each frequency we checked for significant differenceS ( $p<0.05)$ among threshold levels, identified by PTA and ASSR, using a nonparametric test (Wilcoxon MatchedPair Signed-Rank test). There were no statistically-significant differences between groups of patients (group A vs. group B) using a Mann Whitney test except at $4 \mathrm{kHz}$. Moreover, in group A no statistically significant differences were found between the threshold levels obtained by the two methods. Additionally, there was no statistical significance at $0.5 \mathrm{kHz}$ or $1 \mathrm{kHz}$ among group B subjects, while a significant difference was found at 2 and $4 \mathrm{kHz}$ (Table III).

Our analysis revealed that the two methods are substantially equivalent and reliable in determining the hearing threshold and that the correlation between the two methods is greater for low and mid frequencies.

The degree of correlation between threshold levels, obtained by PTA and ASSR, was also studied applying Pearson's test for both groups. As reported in Figure 2, there is a strong and positive correlation at all frequencies investigated, in particular at 0.5 and $4 \mathrm{kHz}$ (those with more data available). In particular, this relationship was significant $(\mathrm{p}<0.001)$ in both groups at $0.5 \mathrm{kHz}$ (Pearson $=0.9(\mathrm{p}<0.001)$ group $\mathrm{B} ; 0.61(\mathrm{p}<0.001)$ group $\mathrm{A})$ and at $4 \mathrm{kHz}($ Pearson $=0.86(\mathrm{p}<0.001)$ group $\mathrm{B} ; 0.81$ $(\mathrm{p}<0.001)$ group A). Also, the threshold levels obtained by ABR and by ASSR were compared using Pearson's test for both groups: the correlation coefficient was 0.63 and $0.74(\mathrm{p}<0.001)$ at 2 and $4 \mathrm{kHz}$ among group $\mathrm{A}$, and was 0.60 and $0.56(\mathrm{p}<0.001)$ in group $\mathrm{B}$.

\section{Discussion}

Congenital hearing loss has been reported to be the most prevalent human communication disorder worldwide ${ }^{15}$. The early identification of hearing loss, through universal neonatal hearing screening programs, and therefore the objective hearing threshold assessment, are crucial to reduce the development of linguistic and cognitive impairment ${ }^{16}{ }^{17}$.

Currently, ABR is still considered the gold standard for prediction of hearing threshold in very young and noncooperative children ${ }^{18-20}$. Nonetheless, it is difficult to ascertain precise and objective information about hearing thresholds in very young children and at certain frequency ranges ${ }^{21}$. Other objective methods tested for the evaluation of mid-low frequencies include the use of tone pip ABR, CE-Chirps and Low-Chirp BERA (LCBERA); very recently, Frank et al. reported that LC-BERA appears to possess a high degree of accuracy in detecting threshold values at low frequencies in their experience with 25 adults with normal hearing. In addition, CE-Chirps have been reported to offer good signal-to-noise ratio when testing mid-low frequencies. However, most of the studies available in the literature so far report experiments on young adults or newborns with normal hearing 22-27.

In recent years, an increasing number of clinical studies have examined the role of ASSR ${ }^{320}{ }^{27-30}$. ASSR offers evoked potentials that can explore both ears simultaneously across several frequencies (range 250 to $8000 \mathrm{~Hz}$ ), including middle-to-low frequencies ${ }^{7931}$; in the present study, 4 cases with uncertain ABR responses showed a better hearing threshold definition by ASSR testing.

Correlation between threshold levels identified by ABR, ASSR and PTA have already been investigated in children with normal hearing ${ }^{31-33}$, while the experiences available in those affected by hearing loss are still very limited ${ }^{20} 34$. Only a few studies have already demonstrated a good correlation between threshold levels identified by ASSR and ABR ${ }^{18}{ }^{19}$; Lin $^{35}$ showed a high correlation between ASSR and ABR estimates at $4 \mathrm{kHz}$; Swanepoel et al. found a correlation between $\mathrm{ABR}$ and ASSR for frequencies between 2 and $4 \mathrm{kHz}$ in normal hearing patients or with conductive hearing loss, and between 1 and $4 \mathrm{kHz}$ in those with sensorineural hearing loss ${ }^{2}$. Also, the relation between ASSR and subject protocols (i.e. play audiometry and/or visual 


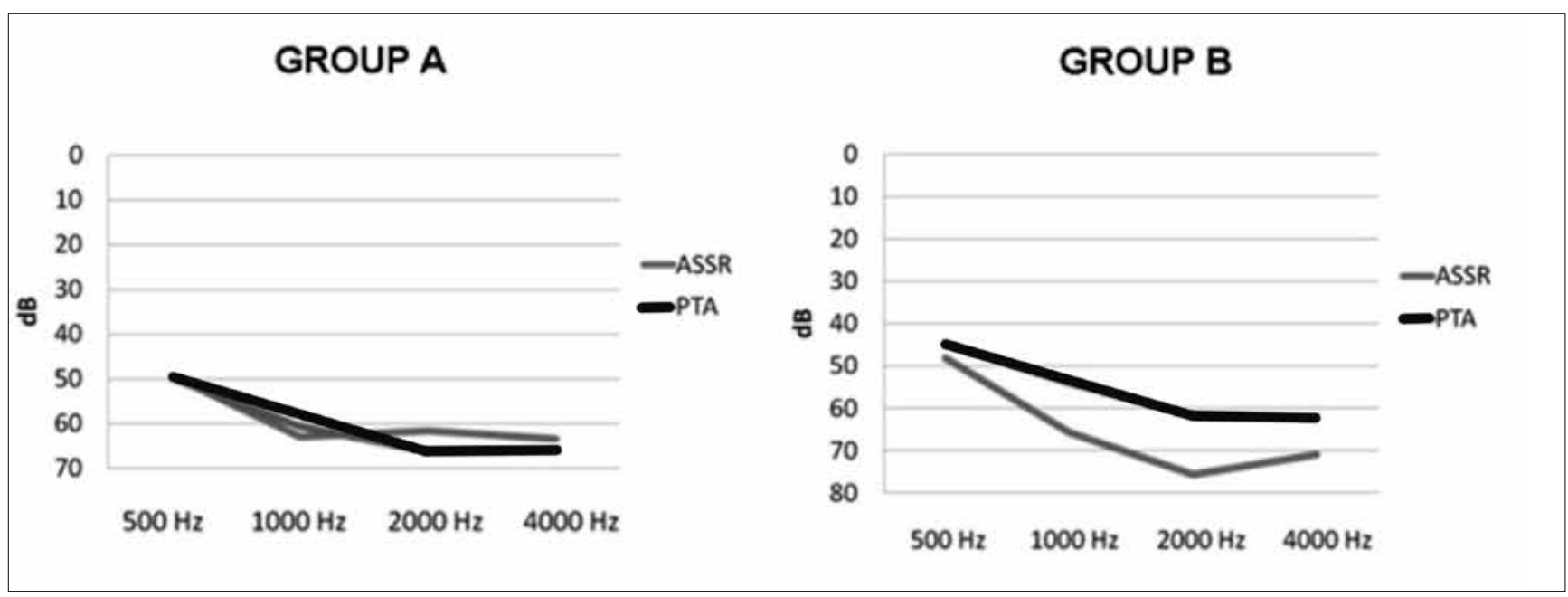

Fig. 1. Groups A and B, showed overall overlapping threshold profiles using pure tone audiometry and ASSR; the average time-interval between audiological tests was 22.41 months for subjects in group $A$ and 4.37 months for group B.

Table III. Differences, in decibels, between the threshold levels obtained by the pure tone audiometry and by ASSR, in groups A and B, at the tested frequencies $(0.25,0.5,1,2$ and $4 \mathrm{kHz})$.

\begin{tabular}{|c|c|c|c|c|c|c|}
\hline & Difference & $250 \mathrm{~Hz}$ & $500 \mathrm{~Hz}$ & $1 \mathrm{kHz}$ & $2 \mathrm{kHz}$ & $4 \mathrm{kHz}$ \\
\hline \multirow[t]{5}{*}{ GROUP B } & $\mathrm{N}$ & 2 & 32 & 13 & 14 & 28 \\
\hline & Range & $-25:-10$ & $-20:+25$ & $-20:+15$ & $-30:+5$ & $-35:+15$ \\
\hline & Mean & -17.5 & -2.2 & -5.4 & -8.6 & -11.2 \\
\hline & St dev & 10.6 & 10.7 & 11.4 & 10.6 & 11.2 \\
\hline & $\begin{array}{c}\text { W (sig) } \\
\text { assr vs aud }\end{array}$ & -- & (0.18ns) & (0.10ns) & $\left(0.01^{\star}\right)$ & $\left(0.00^{\star \star}\right)$ \\
\hline $\begin{array}{l}\text { U Mann Whitney sig } \\
\text { Cases vs controls }\end{array}$ & & $0.80 \mathrm{~ns}$ & $0.40 \mathrm{~ns}$ & $0.43 \mathrm{~ns}$ & $0.21 \mathrm{~ns}$ & $0.002^{*}$ \\
\hline \multirow[t]{6}{*}{ GROUP A } & $\mathrm{N}$ & 3 & 38 & 17 & 12 & 30 \\
\hline & Min-Max & $-30:-15$ & $-20:+30$ & $-20:+25$ & $-25:+20$ & $-35:+20$ \\
\hline & Mean & -21.7 & 0.9 & -1.8 & -0.8 & -1.5 \\
\hline & St. dev & 7.6 & 13.6 & 12.4 & 14.6 & 11.7 \\
\hline & $\begin{array}{c}\text { W (sig) } \\
\text { assr vs aud }\end{array}$ & -- & (0.76 ns) & (0.51ns) & (0.79 ns) & (0.56 ns) \\
\hline & & 250 & 500 & 1 & 2 & 4 \\
\hline \multirow[t]{4}{*}{ TOTAL } & $N$ & 5 & 70 & 30 & 26 & 58 \\
\hline & Mean & -20 & -0.5 & -3.3 & -5.0 & -6.2 \\
\hline & St. Dev & 7.9 & 12.4 & 11.9 & 13.0 & 12.4 \\
\hline & W (sig) & $0.03^{*}$ & (0.53 ns) & (0.11 ns) & $\left(0.04^{\star}\right)$ & $(0.00 * \star)$ \\
\hline
\end{tabular}

reinforcement audiometry) seems to be reliable ${ }^{36} 37$; however, some authors showed differences in threshold levels

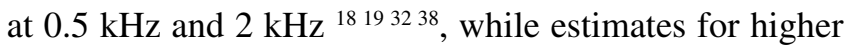
frequencies $(2-4 \mathrm{kHz})$ seem to be more reliable ${ }^{39} 40$. When comparing ASSR threshold levels with tonal audiometry, the correlation was found to be reliable at $0.5 \mathrm{kHz}$ and $2 \mathrm{kHz}$, but was only confirmed in adult subjects $3114142-47$.
In the present study, we investigated the relationship between ABR and ASSR threshold level estimates and PTA hearing thresholds in children. Our findings reveal slight differences in threshold levels at 2 and $4 \mathrm{kHz}$ when comparing PTA to ABR, and when comparing PTA to ASSR, among the groups studied. Furthermore, when considering subjects in group A, there was no significant differ- 


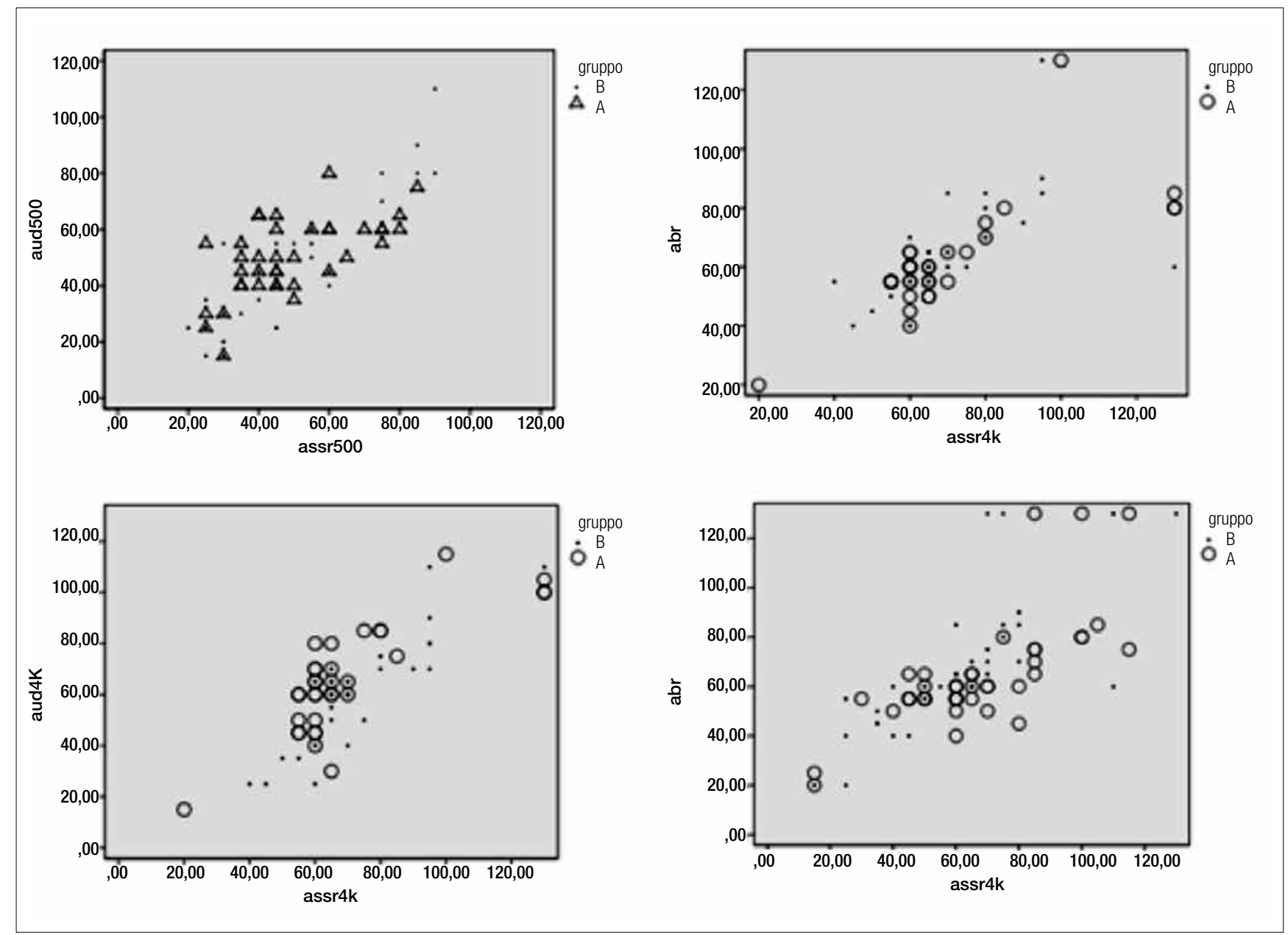

Fig. 2. Degree of correlation between threshold levels, obtained at 0.5 and $4 \mathrm{kHz}$, by PTA and ASSR, as well as those obtained by ABR and by ASSR, applying Pearson's test for both groups (ABR threshold was obtained using a broadband click).

ence between the ASSR and ABR thresholds detected when the children were very young, and the PTA thresholds subsequently identified, later in time, within the same group of children. We also were able to report, for the first time, a reliable correlation between threshold estimations at low frequencies $(0.5 \mathrm{kHz})$ in young children. In previously reported experiments, this correlation was not clear; several authors (i.e. Savio, 1997 and Lins, 1996) argued that this evaluation was difficult probably due to poor neural synchronisation at this frequency, or to a masking effect produced by background noise.

As for small $(10 \mathrm{~dB})$ threshold differences between ASSR and PTA at 2 and $4 \mathrm{kHz}$ among group B subjects, we believe this may represent a genuine difference in sensitivity between the two methods in detecting the hearing threshold, since: (i) other authors have already indicated this difference at 2 and $4 \mathrm{kHz}^{2}$ and (ii) in our experiments, both procedures were performed within this group within a limited time-lag and under the same test conditions. Therefore, ASSR can be used to predict hearing thresholds even in younger children and particularly at mid-tolow frequencies.

A drawback of this study is the absence of tympanometric data: since it is a retrospective study, tympanometry was not available for all cases. Indeed, it is possible that part of the threshold difference between ASSR and PTA at 2 and $4 \mathrm{kHz}$ among group B subjects could also be due to the presence of middle ear effusion (certainly frequent during infancy) at the time of ASSR testing. The presence of middle ear effusion might have some influence on the fact that differences were noted across different frequencies, as also described by other authors ${ }^{48}$. The same consideration could apply for the differences in threshold levels at 2 and $4 \mathrm{kHz}$ in-between PTA and ABR. Finally, the tests used herein (ASSR vs. PTA vs. ABR) were performed in different sessions, and therefore in possibly different middle ear conditions. 


\section{Conclusions}

In conclusion, in light of the present study, ASSR can be considered to be an effective and reliable procedure particularly to predict hearing threshold in children at different ages, and even at lower frequencies (including 0.5 $\mathrm{kHz}$ ). Furthermore, in our opinion, ASSR can be particularly useful in order to: (i) confirm hearing threshold when performed together with other hearing tests (i.e. ABR and/ or otoacoustic emissions) ; (ii) to predict hearing threshold also at lower frequencies (including $0.5 \mathrm{kHz}$ ) especially in younger and non-collaborative children; (iii) to facilitate procedures for the fitting of hearing-aids, particularly focusing on mid-to-low frequencies in very young children.

\section{References}

1 Wrightson AS. Universal newborn hearing screening. Am Fam Physician 2007;75:1349-52.

2 Swanepoel D, Ebrahim S. Auditory steady-state response and auditory brainstem response thresholds in children. Eur Arch Otorhinolaryngol 2009;266:213-9.

3 Rickards FW, Tan LE, Cohen LT, et al. Auditory steady-state evoked potential in newborns. Br J Audiol 1994;28:327-37.

4 Korczal P, Smart J, Delgrado R, et al. Auditory steady-state responses. J Am Acad Audiol 2012;23:146-70.

5 Van Maanen A, Stapells DR. Normal multiple auditory steady-state response thresholds to air-conducted stimuli in infants. J Am Acad Audiol 2009;20:196-207.

6 Vander Werff KR, Brown CJ, Gienapp BA, et al. Comparison of auditory steady-state response and auditory brainstem response thresholds in children. J Am Acad Audiol 2002; $13: 227-35$.

7 Werff KRV, Brown CJ, Gienapp BA, et al. Comparison of auditory steady-state response and auditory brainstem response thresholds in children. J Am Acad Audiol 2002;13:227-35.

8 Kandogan T, Dalgic A. Reliability of Auditory Steady-State Response (ASSR): comparing Thresholds of Auditory SteadyState Response (ASSR) with Auditory Brainstem Response $(A B R)$ in children with severe hearing loss. Indian J Otolaryngol Head Neck Surg 2013;65:604-7.

9 Ahn JH, Lee HS, Kim YJ, et al. Comparing pure-tone audiometry and auditory steady state response for the measurement of hearing loss. Otolaryngol Head Neck Surg 2007;136:966-71.

10 Luts H, Wouters J. Hearing assessment by recording multiple auditory steady-state response: the influence of test duration. Int J Audiol 2004;43:471-8.

11 Luts H, Desloovere C, Kumar A, et al. Objective assessment of frequency-specific hearing thresholds in babies. Int J Pediatr Otorhinolaryngol 2004;8:915-26.

12 Rance G, Rickards FW. Prediction of hearing threshold in infants using auditory steady-state evoked potentials. J Am Acad Audiol 2002;13:236-45.
13 Rance G, Roper R, Simons L, et al. Hearing threshold estimation in infants using auditory steady-state responses. J Am Acad Audiol 2005;16:291-300.

14 Ciorba A, Hatzopoulos S, Petruccelli J, et al. Identifying congenital hearing impairment: preliminary results from a comparative study using objective and subjective audiometric protocols. Acta Otolaryngologica Ital 2013;33:29-35.

15 American Speech-Language-Hearing Association (ASHA) (2012) . Guidelines for Audiologic Screening Available from: http://www.asha.org/policy/GL1997- 00199.htm

16 Hilú MRPB, Zeigelboim BS. O conhecimento, a valorização da triagem auditiva neonatal e a intervenção precoce da perda auditiva. Rev CEFAC 2007;9:563-70.

17 Grupo de Apoio à Triagem Auditiva Neonatal Universal (GATANU) (2007) [cited 2012 Mar 19]. Available from: http:// www. gatanu.org

18 Rodrigues GR, Lewis DR, Fichino SN. Steady-state auditory evoked responses in audiological diagnosis in children: a comparison with brainstem evoked auditory responses. Braz J Otorhinolaryngol 2010;76:96-101.

19 Rodrigues GR, Lewis DR. Threshold prediction in children with sensorineural hearing loss using the auditory steadystate responses and tone-evoked auditory brain stem response. Int J Pediatr Otorhinolaryngol 2010;74:540-6.

20 Chou Y-F, Chen P-R, Yu S-H, et al. Using multi-stimulus auditory steady-state response to predict hearing thresholds in high-risk infants. Eur Arch Otorhinolaryngol 2012;269:73-9.

21 Parving A. Prevalence of congenital hearing impairment and risk factors. Neonatal hearing screening. In: Grandori F, Lutman M, editors. The European Consensus Development Conference on Neonatal Hearing Screening. Milan; 1998. p. 6-10.

22 Frank J, Baljić I, Hoth S, et al. The accuracy of objective threshold determination at low frequencies: comparison of different auditory brainstem response $(A B R)$ and auditory steady state response (ASSR) methods. Int J Audiol 2017;56:337-45.

23 Ferm I, Lightfoot G, Stevens J. Comparison of ABR response amplitude, test time, and estimation of hearing threshold using frequency specific chirp and tone pip stimuli in newborns. Int J Audiol 2013;52:419-23.

${ }^{24}$ Çelik O, Eskiizmir G, Uz U. A Comparison of thresholds of auditory steady-state response and auditory brainstem response in healthy term babies. J Int Adv Otol 2016;12:277-81.

25 François M, Dehan E, Carlevan M, et al. Use of auditory steady-state responses in children and comparison with other electrophysiological and behavioral tests. Eur Ann Otorhinolaryngol Head Neck Dis 2016;133:331-5.

26 Michel F, Jørgensen KF. Comparison of threshold estimation in infants with hearing loss or normal hearing using auditory steady-state response evoked by narrow band CE-chirps and auditory brainstem response evoked by tone pips. Int $\mathrm{J}$ Audiol 2017;56:99-105.

27 Picciotti PM, Giannantonio S, Paludetti G, et al. Steady state 
auditory evoked potentials in normal hearing subjects: evaluation of threshold and testing time. ORL J Otorhinolaryngol Relat Spec 2012;74:310-4.

28 Eggermont JJ. The inadequacy of click-evoked auditory brainstem responses in audiological applications. Ann N Y Acad Sci 1982;388:707-9.

29 Calil DB. Achados dos Potenciais Evocados Auditivos de Estado Estável em crianças ouvintes e crianças portadoras de deficiência auditiva sensorial [dissertação]. São Paulo (SP): Pontifícia Universidade Católica 2005.

30 Cone-Wesson B, Dowell RC, Tomlin D, et al. The auditory steady-state response: comparisons with the auditory brainstem response. J Am Acad Audiol 2002;13:173-87.

31 Linares AE, Costa-Filho AO, Martinez M. Auditory steady state response in pediatric audiology. Braz J Otorhinolaryngol 2010;76:723-8.

32 Han D, Mo L, Liu H, et al. Threshold estimation in children using auditory steady-state responses to multiple simultaneous stimuli. ORL J Otorhinolaryngol Relat Spec 2006;68:64-8.

33 Ferraz OB, Freitas SV, Marchiori LLM. Análise das respostas obtidas por Potenciais Evocados Auditivos de Estado Estável em indivíduos normais. Rev Bras Otorrinolaringol 2002;68:480-6.

34 Rance G, Dowell RC, Rickards FW, et al. Steady-state evoked potential and behavioral hearing threshold in a group of children absent click-evoked auditory brainstem response. Ear Hear 1998;19:48-61.

35 Lin Yu-Hsing, Ho Hsu-Chueh, Wu Hung-Pin. Comparison of auditory steady-state responses and auditory brainstem responses in audiometric assessment of adults with sensorineural hearing loss. Auris Nasus Larynx 2009;36:140-5.

36 Martínez Fernández A, Alañón Fernández MA, Ayala Martínez LF, et al. Comparative study between auditory steadystate responses, auditory brain-stem responses and liminar tonalaudiometry. Acta Otorrinolaringol Esp 2007;58:290-5.

37 Dimitrijevic A, Sasha John M, Van Roon P, et al. Estimating the audiogram using multiple auditory steady state responses. J Am Acad Audiol 2002;13:205-24.

38 Farias VB, Sleifer P, Pauletti LF, et al. Correlation of the findings of auditory steady-state evoked potential and of be- havioral hearing assessment in infants with sensorineural hearing loss. Codas 2014;26:226-30.

39 Rance G, Briggs RJS. Assessment of hearing in infants with moderate to profound impairment: the Melbourne experience with auditory steady-state evoked potential testing. Ann Otol Rhinol Laryngol Suppl 2002;189:22-8.

40 Rance G, Dowell RC, Rickards FW, et al. Steady-state evoked potential and behavioral hearing threshold in a group of children absent click-evoked auditory brainstem response. Ear Hear 1998;19:48-61.

41 Schmulian D, Swanepoel D, Hugo R. Predicting puretone thresholds with dichotic multiple frequency auditory steady state responses. J Am Acad Audiol 2005;16:5-17.

42 Duarte JL, de Freitas Alvarenga K, Manfrini Garcia T, et al. Resposta auditiva de estado estável na avaliação auditiva: aplicação clínica). Pro Fono 2008;20:105-10.

43 Picton TW, Skinner CR, Champagne SC, et al. Potentials evoked by the sinusoidal modulation of the amplitude or frequency of a tone. J Acoust Soc Am 1987;82:165-78.

44 Rickards FW, Clark GM. Steady-state evoked potentials in humans to amplitude modulated tones. In: Nodar RH, Barber C, editors. Evoked potentials II. Boston: Butterworth; 1984. p. 163-8.

45 Tolga Kandogan, Abdullah Dalgic. Reliability of Auditory Steady-State Response (ASSR): comparing thresholds of Auditory Steady-State Response (ASSR) with Auditory Brainstem Response (ABR) in children with severe hearing loss. Indian J Otolaryngol Head Neck Surg 2013;65:S604S607.

46 Lins OG, Picton TW, Boucher BL, et al. Frequency-specific-audiometry using steady-state responses. Ear Hearing 1996;17:81-96.

47 Savio G, Pérez-Ábalo MC, Valdés JL, et al. Potenciales evocados auditivos de estado estable a múltiples frecuencias: una nueva alternativa para evaluar la audición en forma objetiva. Acta Otorrinolaringol Esp 1997;25:87-97.

48 Vargas Garcia M, Frasson de Azevedo M, Pinto Vieira Biaggio E, et al. Auditory steady-state responses air and bone conducted in children from zero to six months with and without conductive impairments. CEFAC 2014;16:699-706. 